Tropical Journal of Pharmaceutical Research September 2014; 13 (9): 1549-1554

ISSN: $1596-5996$ (print); 1596-9827 (electronic)

(c) Pharmacotherapy Group, Faculty of Pharmacy, University of Benin, Benin City, 300001 Nigeria.

All rights reserved.

Available online at http://www.tjpr.org

Original Research Article

http://dx.doi.org/10.4314/tjpr.v13i9.24

\title{
A Bibliometric Study of Community Pharmacy-Based Research Activity in Middle Eastern Arab Countries: 2003 - 2012
}

\author{
Waleed M Sweileh ${ }^{1 \star}$, Sa'ed H Zyoud ${ }^{1}$, Ansam F Sawalha ${ }^{1}$ and Samah W Al-Jabi ${ }^{2}$ \\ ${ }^{1}$ Department of Pharmacology/Toxicology, ${ }^{2}$ Department of Clinical Pharmacy and Pharmacotherapy, College of Medicine and \\ Health Sciences, An-Najah National University, Nablus, Palestine
}

*For correspondence: Email: waleedsweileh@yahoo.com, waleedsweileh@najah.edu; Tel: +970 599 225906, Fax: +970 9 2345982

Revised accepted: 17 July 2014

\begin{abstract}
Purpose: To analyze community pharmacy based research in Arab countries.

Methods: Comprehensive review of the literature indexed by Scopus was conducted. Data from Jan 01, 2003 till December 31, 2013 was searched for documents with specific words pertaining to "community pharmacy" in any one of the 13 Middle Eastern Arab countries. The quality of publication was assessed using h-index obtained from Scopus and Impact Factor (IF) obtained from Journal Citation Report (JCR) Results: A total of 93 documents were retrieved with an h-index of 9 . Thirty eight documents (40.9\%) were published in journals not listed in JCR and therefore had no IF. The sum of the IF of the 93 documents was 64.9 with a mean of $1.3 \pm 2.01$. The total number of citations was 338 with a mean of $3.6 \pm 6.4$ citations per document. The highest community pharmacy-based research was from Kingdom of Saudi Arabia (KSA) (32.3 \%) followed by United Arab Emirates (UAE) (17.2 \%), Jordan (16.1\%), Kuwait (11.8\%) and Qatar (10.8\%). International cooperation was highest with Malaysia (9.7\%) followed by Pakistan (7.5\%), United Kingdom (UK) (8.6\%), and Australia (6.5\%).

Conclusion: The quantity and quality of community pharmacy-based research originating from Middle Eastern Arab countries was low. More effort is needed to bridge the gap in community pharmacy-based research and to promote better community pharmacy services in Middle Eastern Arab countries.
\end{abstract}

Keywords: Community pharmacy, Middle East, Bibliometric review

Tropical Journal of Pharmaceutical Research is indexed by Science Citation Index (SciSearch), Scopus, International Pharmaceutical Abstract, Chemical Abstracts, Embase, Index Copernicus, EBSCO, African Index Medicus, JournalSeek, Journal Citation Reports/Science Edition, Directory of Open Access Journals (DOAJ), African Journal Online, Bioline International, Open-J-Gate and Pharmacy Abstracts

\section{INTRODUCTION}

In the past few years, several publications have described the community pharmacy profession in the Arab world [1,2]. Authors of these publications reached a conclusion that community pharmacy is not a well-established health profession. Despite this, the general public in the Arab world reported positive perception and attitude toward community pharmacy profession and demanded more roles for community pharmacists in the health system [27].

Bibliometric analysis is a useful tool to obtain information about the current state of research in particular areas and allows researchers to identify and undertake new lines of research. Analysis of the scientific literature concerning community pharmacies have been published $[8,9]$. In the Middle East, several studies have been published about pharmacy profession and 
education. However, none was published to analyze the quantity and quality of research in the field of pharmacy in general, and community pharmacy in particular. Therefore, this study was conducted to analyze the quantity and quality of community pharmacy based research during the last decade $(2003-2012)$. Such study will lead to better understanding of the current and future community pharmacy practice in the Middle East. Furthermore, the results of this study will help people in academia and in pharmaceutical association to shape community pharmacy profession in the next decade. In addition, the momentum for research activity needs to be maintained through continuous analysis of pharmacy publication from researchers in the region to provide feedback to academic institutions and education planners.

\section{EXPERIMENTAL}

Comprehensive online search was performed using Scopus which is one of the world's largest abstract, and citation databases of peer-reviewed literature. Scopus contains 41 million records and covers nearly 18,000 titles from 5000 publishers worldwide and provides $100 \%$ Medline coverage [10]. The key words or "medical subject headings (MeSH)" entered in Scopus to accomplish the objective of this study were "Community Pharmacy", "Community Pharmacist", or "Community Pharmacies", or "Community Pharmaceutical Services" or "Community Pharmaceutical Service" as "title, keywords, abstract". Thereafter, all thirteen Arab countries in Middle East were entered as country affiliation (i.e. Egypt, Syria, Lebanon, Jordan, Iraq, King of Saudi Arabia (KSA), Kuwait, Bahrain, State of Palestine, United Arab Emirates (UAE), Yemen, Oman and Qatar). The study period was chosen to be from January 1, 2003 till December 31, 2012.

Subject areas selected for this research were: health sciences, life sciences, social sciences and physical sciences. The resultant search was as follows: "TITLE-ABS-KEY("Community Pharmacy") or TITLE-ABS-KEY("Community Pharmacist") or TITLE-ABS-KEY("Community Pharmacies") or TITLE-ABS-KEY("Community Pharmaceutical Service") or TITLE-ABSKEY("Community Pharmaceutical Services") and AFFILCOUNTRY(palestine) or AFFILCOUNTRY(jordan)

AFFILCOUNTRY(syrian)

AFFILCOUNTRY(lebanon)

AFFILCOUNTRY(iraq)

AFFILCOUNTRY(yemen)

AFFILCOUNTRY(egypt)
AFFILCOUNTRY(arabia)

or

AFFILCOUNTRY(bahrain)

AFFILCOUNTRY(qatar)

AFFILCOUNTRY(united

arab)

or

AFFILCOUNTRY(oman)

or

AFFILCOUNTRY(kuwait) and PUBYEAR > 2002 and PUBYEAR < 2013"

Data from Scopus were exported to Excel then to IBM ${ }^{\circledR}$ SPSS $\AA^{\circledR}$ Statistics 20 software package (IBM, New York, USA) for analysis and graphics. The $h$-index for the collected data from Scopus was presented. The $\mathrm{h}$-index represents the number of citations received for each of the articles in descending order and the h-graph measures the impact of a set of documents and displays the number of citations per article. The journal's impact factor (IF) was evaluated using the Journal Citation Report (Web of Knowledge) [11]. For citation and IF, both total and median values were presented.

\section{RESULTS}

Using the methodology stated, 93 documents were retrieved; an average of 9.3 documents per year from 13 Arab Middle Eastern countries. Table 1 shows the annual number of documents published during the 2003 - 2012. The table indicates low research productivity during the past decade with a slight increase in the past 2 years.

The total number of authors listed for the 93 documents was 275 with a mean \pm SD of $3 \pm 1.4$ and a median (Q1 - Q3) of $3(2-4)$. Eighteen documents $(19.4 \%)$ were published by a single author. Table 2 shows the frequency of documents stratified by the number of authors.

Eighty six documents were categorized as original research articles; four were categorized as review articles and three as letter to the editor.

The retrieved documents were published in 50 international, regional and local peer reviewed journals (Table 3 ). Fourteen articles (15\%) were published in the International Journal of Clinical Pharmacy (formerly known as Pharmacy World and Science) whereas 9 (9.7\%) were published in the International Journal of Pharmacy Practice and $7(7.5 \%)$ were published in Pharmacy Practice Journal.

Thirty eight documents (38/93; $40.9 \%$ ) were published in journals that had no official IF (Table $3)$. 
Table 1: Annual number of community pharmacy based publication in 13 Middle Eastern Arab Countries

\begin{tabular}{lccccccccccc}
\hline Year & 2003 & 2004 & 2005 & 2006 & 2007 & 2008 & 2009 & 2010 & 2011 & 2012 & Total \\
\hline $\begin{array}{l}\text { Number of } \\
\text { publications }\end{array}$ & 3 & 5 & 4 & 5 & 5 & 11 & 11 & 9 & 17 & 23 & 93 \\
\hline
\end{tabular}

Table 2: Frequency of articles stratified by the Number of authors

\begin{tabular}{lcccccccc}
\hline $\begin{array}{l}\text { Number of authors per } \\
\text { article }\end{array}$ & $\mathbf{1}$ & $\mathbf{2}$ & $\mathbf{3}$ & $\mathbf{4}$ & $\mathbf{5}$ & $\mathbf{6}$ & $\mathbf{7}$ & Total \\
\hline Frequency & 18 & 18 & 25 & 20 & 7 & 4 & 1 & 93 \\
\hline
\end{tabular}

Table 3: List of journals in which the 93 documents were published

\begin{tabular}{|c|c|c|c|}
\hline Journal & Frequency & $\%$ & IF (2011)* \\
\hline American Journal of Pharmaceutical Education & 2 & 2.2 & 1.205 \\
\hline Annals of Pharmacotherapy & 1 & 1.1 & 2.126 \\
\hline Asian Journal of Pharmaceutical and Clinical Research & 1 & 1.1 & NA \\
\hline Asian Journal of Pharmaceutics & 1 & 1.1 & NA \\
\hline BMC Public Health & 1 & 1.1 & 1.997 \\
\hline British Journal of Clinical Pharmacology & 1 & 1.1 & 2.958 \\
\hline Drugs and Aging & 1 & 1.1 & 2.671 \\
\hline Eastern Mediterranean Health Journal & 4 & 4.3 & NA \\
\hline European Journal of Clinical Pharmacology & 1 & 1.1 & 2.845 \\
\hline European Journal of General Medicine & 1 & 1.1 & NA \\
\hline European Respiratory Journal & 1 & 1.1 & 5.895 \\
\hline Family Practice & 1 & 1.1 & 1.503 \\
\hline HealthMED & 1 & 1.1 & 0.435 \\
\hline Indian Journal of Pharmaceutical Education and Research & 1 & 1.1 & 0.106 \\
\hline Indian Journal of Pharmaceutical Sciences & 1 & 1.1 & 0.626 \\
\hline Informatics in Primary Care & 1 & 1.1 & NA \\
\hline International Journal of Antimicrobial Agents & 1 & 1.1 & 4.128 \\
\hline International Journal of Clinical Pharmacy & 7 & 7.5 & 1.215 \\
\hline International Journal of Pharmacy and Pharmaceutical Sciences & 1 & 1.1 & NA \\
\hline International Journal of Pharmacy Practice & 9 & 9.7 & NA \\
\hline International Journal of Risk and Safety in Medicine & 1 & 1.1 & NA \\
\hline Internet Journal of Pharmacology & 1 & 1.1 & NA \\
\hline Jordan Journal of Pharmaceutical Sciences & 1 & 1.1 & NA \\
\hline Journal of Applied Pharmaceutical Science & 2 & 2.2 & NA \\
\hline Journal of Clinical Pharmacy and Therapeutics & $\overline{1}$ & 1.1 & 1.57 \\
\hline Journal of Infection in Developing Countries & 1 & 1.1 & 1.191 \\
\hline Journal of Medical Sciences & 1 & 1.1 & NA \\
\hline Journal of Pharmacy Practice and Research & 3 & 3.2 & NA \\
\hline Journal of Pharmacy Technology & 3 & 3.2 & NA \\
\hline Journal of Social and Administrative Pharmacy & 1 & 1.1 & NA \\
\hline Journal of the Pakistan Medical Association & 1 & 1.1 & NA \\
\hline Latin American Journal of Pharmacy & 1 & 1.1 & 0.288 \\
\hline Libyan Journal of Medicine & 1 & 1.1 & 0.179 \\
\hline Life Science Journal & 1 & 1.1 & NA \\
\hline Medical Principles and Practice & 3 & 3.2 & 0.887 \\
\hline Neurosciences & 1 & 1.1 & 0.094 \\
\hline Oman Medical Journal & 1 & 1.1 & NA \\
\hline Open Drug Safety Journal & 1 & 1.1 & NA \\
\hline Patient Education and Counseling & 1 & 1.1 & 2.305 \\
\hline Patient Preference and Adherence & 1 & 1.1 & 1.143 \\
\hline Pharmaceutical Journal & 1 & 1.1 & NA \\
\hline Pharmacy Practice & 7 & 7.5 & NA \\
\hline Pharmacy World and Science & 7 & 7.5 & 1.215 \\
\hline Research in Social and Administrative Pharmacy & 1 & 1.1 & 2.35 \\
\hline Research Journal of Medical Sciences & 1 & 1.1 & NA \\
\hline Saudi Medical Journal & 1 & 1.1 & 0.520 \\
\hline Saudi Pharmaceutical Journal & 6 & 6.5 & 0.662 \\
\hline Respirator Care & 1 & 1.1 & 2.01 \\
\hline Substance Use and Misuse & 1 & 1.1 & 1.104 \\
\hline Tropical Journal of Pharmaceutical Research & 1 & 1.1 & 0.820 \\
\hline
\end{tabular}




\begin{tabular}{|c|c|c|c|}
\hline Journal & Frequency & $\%$ & IF (2011)* \\
\hline American Journal of Pharmaceutical Education & 2 & 2.2 & 1.205 \\
\hline Annals of Pharmacotherapy & 1 & 1.1 & 2.126 \\
\hline Asian Journal of Pharmaceutical and Clinical Research & 1 & 1.1 & NA \\
\hline Asian Journal of Pharmaceutics & 1 & 1.1 & NA \\
\hline BMC Public Health & 1 & 1.1 & 1.997 \\
\hline British Journal of Clinical Pharmacology & 1 & 1.1 & 2.958 \\
\hline Drugs and Aging & 1 & 1.1 & 2.671 \\
\hline Eastern Mediterranean Health Journal & 4 & 4.3 & NA \\
\hline European Journal of Clinical Pharmacology & 1 & 1.1 & 2.845 \\
\hline European Journal of General Medicine & 1 & 1.1 & NA \\
\hline European Respiratory Journal & 1 & 1.1 & 5.895 \\
\hline Family Practice & 1 & 1.1 & 1.503 \\
\hline HealthMED & 1 & 1.1 & 0.435 \\
\hline Indian Journal of Pharmaceutical Education and Research & 1 & 1.1 & 0.106 \\
\hline Indian Journal of Pharmaceutical Sciences & 1 & 1.1 & 0.626 \\
\hline Informatics in Primary Care & 1 & 1.1 & NA \\
\hline International Journal of Antimicrobial Agents & 1 & 1.1 & 4.128 \\
\hline International Journal of Clinical Pharmacy & 7 & 7.5 & 1.215 \\
\hline International Journal of Pharmacy and Pharmaceutical Sciences & 1 & 1.1 & NA \\
\hline International Journal of Pharmacy Practice & 9 & 9.7 & NA \\
\hline International Journal of Risk and Safety in Medicine & 1 & 1.1 & NA \\
\hline Internet Journal of Pharmacology & 1 & 1.1 & NA \\
\hline Jordan Journal of Pharmaceutical Sciences & 1 & 1.1 & NA \\
\hline Journal of Applied Pharmaceutical Science & 2 & 2.2 & NA \\
\hline Journal of Clinical Pharmacy and Therapeutics & 1 & 1.1 & 1.57 \\
\hline Journal of Infection in Developing Countries & 1 & 1.1 & 1.191 \\
\hline Journal of Medical Sciences & 1 & 1.1 & NA \\
\hline Journal of Pharmacy Practice and Research & 3 & 3.2 & NA \\
\hline Journal of Pharmacy Technology & 3 & 3.2 & NA \\
\hline Journal of Social and Administrative Pharmacy & 1 & 1.1 & NA \\
\hline Journal of the Pakistan Medical Association & 1 & 1.1 & NA \\
\hline Latin American Journal of Pharmacy & 1 & 1.1 & 0.288 \\
\hline Libyan Journal of Medicine & 1 & 1.1 & 0.179 \\
\hline Life Science Journal & 1 & 1.1 & NA \\
\hline Medical Principles and Practice & 3 & 3.2 & 0.887 \\
\hline Neurosciences & 1 & 1.1 & 0.094 \\
\hline Oman Medical Journal & 1 & 1.1 & NA \\
\hline Open Drug Safety Journal & 1 & 1.1 & NA \\
\hline Patient Education and Counseling & 1 & 1.1 & 2.305 \\
\hline Patient Preference and Adherence & 1 & 1.1 & 1.143 \\
\hline Pharmaceutical Journal & 1 & 1.1 & NA \\
\hline Pharmacy Practice & 7 & 7.5 & NA \\
\hline Pharmacy World and Science & 7 & 7.5 & 1.215 \\
\hline Research in Social and Administrative Pharmacy & 1 & 1.1 & 2.35 \\
\hline Research Journal of Medical Sciences & 1 & 1.1 & NA \\
\hline Saudi Medical Journal & 1 & 1.1 & 0.520 \\
\hline Saudi Pharmaceutical Journal & 6 & 6.5 & 0.662 \\
\hline Respirator Care & 1 & 1.1 & 2.01 \\
\hline Substance Use and Misuse & 1 & 1.1 & 1.104 \\
\hline Tropical Journal of Pharmaceutical Research & 1 & 1.1 & 0.820 \\
\hline Total & 93 & 100.0 & 64.92 \\
\hline
\end{tabular}

Abbreviations: $N A=$ not available; IF = impact factor; *Impact factor was reported according to Institute for Scientific Information (ISI) journal citation reports (JCR) 2011

Only 1 paper was published in a journal with an IF $>5$. The sum of the IF of the entire documents was 64.9 with a mean of $1.3 \pm 2.01$ and a median (Q1-Q3) of $0.2(0-2)$. The total number of citations, at the time of manuscript writing, was 338 with a mean of $3.6 \pm 6.4$ and median (Q1 Q3) of $1(0-4.5)$. Of the 93 documents considered for the $\mathrm{h}$ index, 9 have been cited at least 9 times.
When data were analyzed by country, community pharmacy based research was highest from KSA (32.3 \%) followed by UAE (17.2 \%), Jordan (16.1 $\%)$, Kuwait (11.8\%) and Qatar (10.8\%); (Table $4)$.

International cooperation in community pharmacy research was highest with Malaysia (9.7\%) 
Table 4: Bibliometric analysis of the 93 documents by country

\begin{tabular}{|c|c|c|c|c|c|c|c|}
\hline Country & $\begin{array}{c}\text { Number of } \\
\text { articles } \\
\mathbf{N}=93\end{array}$ & $\begin{array}{c}\text { Total } \\
\text { citations }\end{array}$ & $\begin{array}{l}\text { Median } \\
\text { (Q1-Q3) } \\
\text { Citation }\end{array}$ & Total IF & Median IF & $\begin{array}{c}\mathbf{H} \\
\text { index }\end{array}$ & $\begin{array}{c}\text { Number (\%) of } \\
\text { documents with } \\
\text { international } \\
\text { authors }\end{array}$ \\
\hline KSA & $30(32.3 \%)$ & 45 & $0(0-2)$ & 7.33 & $0(0-0.66)$ & 4 & $20(66.7)$ \\
\hline UAE & $16(17.2 \%)$ & 21 & $0(0-1)$ & 4.5 & $0(0-1)$ & 3 & $10(47.6)$ \\
\hline Jordan & $15(16.1 \%)$ & 171 & $7(2-16)$ & 24.82 & $1.2(0.5-2.3)$ & 7 & $10(66.7)$ \\
\hline Kuwait & $11(11.8 \%)$ & 46 & $3(2-7)$ & 12.35 & $\begin{array}{c}1.215(0.9- \\
1.6)\end{array}$ & 4 & 8 (72.7) \\
\hline Qatar & $10(10.8 \%)$ & 25 & $0(0-1)$ & 8.4 & $1.2(0-1.22)$ & 2 & $5(50)$ \\
\hline Palestine & $8(8.6 \%)$ & 18 & $1(0-3.8)$ & 3.5 & $0(0-0.3)$ & 3 & $2(25)$ \\
\hline Lebanon & $4(4.3 \%)$ & 18 & $\begin{array}{c}3(0.25- \\
10.25)\end{array}$ & 5.02 & $1.2(0-2.6)$ & 2 & $0(0)$ \\
\hline Egypt & $3(3.2 \%)$ & 3 & 0 & 1.2 & 0 & 1 & $2(66.7)$ \\
\hline Oman & $1(1.1 \%)$ & 0 & 0 & 0 & 0 & 0 & $0(0)$ \\
\hline Bahrain & $0(0 \%)$ & 0 & 0 & 0 & 0 & 0 & $0(0)$ \\
\hline Syrian & $0(0 \%)$ & 0 & 0 & 0 & 0 & 0 & $0(0)$ \\
\hline
\end{tabular}

Abbreviations: IF = impact factor; UAE= United Arab Emirates; KSA= King of Saudi Arabia; $Q 1-Q 3=$ Iower quartile - upper quartile

followed by Pakistan (7.5\%), UK (8.6\%), and Australia (6.5\%); (Table 5). When the 13 Middle East countries were compared with regard to quality, papers published by Jordanian researchers had the highest $h$ index followed by those from Saudi Arabia and Kuwait. The same applies to total IF where Jordanian researchers published in journals with higher IF than those from other Arab countries in the Middle East.

Table 5: Countries involved in international cooperation in community pharmacy-based research with Middle Eastern Arab countries

\begin{tabular}{lc}
\hline International cooperation & $\begin{array}{c}\text { Number (\%) } \\
\text { of articles }\end{array}$ \\
\hline Malaysia & $9(9.7)$ \\
Pakistan & $7(7.5)$ \\
United Kingdom & $8(8.6)$ \\
United States of America & $2(2.2)$ \\
& \\
Australia & $6(6.5)$ \\
Finland & $3(32.2)$ \\
New Zealand & $3(32.2)$ \\
India & $3(32.2)$ \\
Czech Republic & $1(1.1)$ \\
Ghana & $1(1.1)$ \\
Sudan & $1(1.1)$ \\
Switzerland & $1(1.1)$ \\
Canada & $1(1.1)$ \\
\hline
\end{tabular}

\section{DISCUSSION}

In the present study, bibliometric indicators were used to describe the scientific activity in community pharmacies in 13 Middle Eastern Arab countries during 2003 - 2012. Based on authors' knowledge, this is the first article that analyzed the quantity and quality of community pharmacy based research from the Arab world. Research indicators showed that research activity in this field is neglected in the Arab world. A total of 93 papers from 13 Middle East countries regarding community pharmacy aspects (9.3 papers per year) represent a low rate of publication. Similar rate of low productivity of scientific articles in community pharmacies from other developing countries have been described as low [9].

Our study showed that scientific output in community pharmacy research has notably increased during the study period. Less than third of the articles were published in the first 5 years, between 2003 and 2007, whereas more than $60 \%$ of the articles were published between 2008 and 2012. The increase in the number of articles published appears to be related to the presence of specialized PhD holders in the field of pharmacy practice and pharmaceutical care particularly in Jordanian and Saudi universities. It was also notable that Malaysia came first in international cooperation regarding community pharmacy research in the Middle East countries. Recently, many PhD students from the Middle East pursued their graduate pharmacy education in Malaysia where the concept of social pharmacy and pharmacy practice is being emphasized at the research and academic levels.

Many of the studies carried out were descriptive studies of community pharmacy practice and there was no study involving controlled randomized experimental designs. The results may, however, serve as an indictment of 
pharmacy researchers for failing to carry out research in this discipline. The community pharmacy practice aspects in Arab world is neglected in terms of scientific publication output as compared with the publication of papers in other fields of pharmaceutical other medical sciences. There is a need to undertake research into community pharmacists' activities and to systematically assess their education and training needs.

\section{Limitations of the study}

This study is limited by the fact that publications from Middle East countries in journals that are not indexed in Scopus were not included in the analysis. Therefore, it is possible that the number of publications analyzed in this study did not exactly represent all community pharmacy-based research activity.

\section{CONCLUSION}

Only a small number of research or review articles on community pharmacy activity were available. This is perhaps indicative of low emphasis on community pharmacy research in the countries studied. Thus, there is need for the countries concerned to focus on areas such as medicine utilization and appropriate use of medicines. The main goal of our study is to direct attention and to open doors for a scientific discussion among professionals and academics about community pharmacy-based research. Academic institutions in the Middle East will need to initiate community pharmacy specialized programs and to strengthen research collaboration with international researchers and institutions in which community pharmacy research has evolved.

\section{REFERENCES}

1. Al-Hassan MI. A look at community pharmacy practice in Saudi Arabia. Research Journal of Medical Sciences. 2009; 3:111-4.

2. Hasan S, Sulieman $H$, Chapman C, Stewart K, Kong DCM. Community pharmacy in the United Arab Emirates: Characteristics and workforce issues. International Journal of Pharmacy Practice. 19:392-9.

3. Awad A, Abahussain E. Health promotion and education activities of community pharmacists in Kuwait. Pharmacy World and Science.32:146-53.

4. Bawazir SA. Consumer attitudes towards community pharmacy services in Saudi Arabia. International Journal of Pharmacy Practice. 2004; 12:83-9.

5. Bawazir SA. Attitude of community pharmacists in Saudi Arabia towards adverse drug reaction reporting. Saudi Pharmaceutical Journal. 2006; 14:75-83.

6. Hamoudi NM, Shirwaikar AA, Ali HS, Al Ayoubi El. Pharmaceutical consultation in UAE community pharmacies. Indian Journal of Pharmaceutical Sciences. 73:404-8.

7. Wazaify M, Al-Bsoul-Younes A, Abu-Gharbieh E, Tahaineh $L$. Societal perspectives on the role of community pharmacists and over-the-counter drugs in Jordan. Pharmacy World and Science. 2008;30:884-91.

8. Sokar-Todd HB, TR. E. Community pharmacy practice research: a systematic review of the past 32 years. . Can Pharm J. 2003; 136(8):26-38.

9. Basak SC, Sathyanarayana D. Community pharmacy based research activity in India: A bibliometric study of the past ten years. South Med Rev.3:7-10.

10. Scopus. SciVerse Scopus fact sheet. SciVerse® Scopus, Elsevier B.V., Amsterdam, Netherlands. Available from:

http://www.info.sciverse.com/UserFiles/2508.SciVers e.Scopus_Facts_Figures\%28LR\%29.pdf. [Accessed on 2012 Oct 19].

11. JCR. http://thomsonreuters.com/journal-citation-reports/. 2003-2012. 